\title{
Overexpression of heat shock protein 70 in R6/2 Huntington's disease mice has only modest effects on disease progression
}

\author{
Oskar Hansson $^{\mathrm{a}, 1}$, Jesper Nylandsted ${ }^{\mathrm{b}}$, Roger F. Castilho ${ }^{\mathrm{c}}$, Marcel Leist ${ }^{\mathrm{d}}$, Marja Jäättelä ${ }^{\mathrm{b}}$, \\ Patrik Brundin ${ }^{\mathrm{a}, *}$ \\ ${ }^{a}$ Section for Neuronal Survival, Wallenberg Neuroscience Center, BMC A10, Department of Physiological Sciences, Lund University, 22184 Lund, \\ Sweden \\ ${ }^{\mathrm{b}}$ Apoptosis Laboratory, Danish Cancer Society, Strandboulevarden 49, Copenhagen, Denmark \\ ${ }^{\mathrm{c}}$ Department of Clinical Pathology, School of Medical Sciences, State University of Campinas, Campinas, Brazil \\ ${ }^{d}$ Section of Neuroprotection, H. Lundbeck A/S, Ottiliavej 9, DK-2500 Valby, Denmark
}

\begin{abstract}
Huntington's disease (HD) is a neurodegenerative disorder caused by expansion of a polyglutamine tract in a protein called huntingtin. The inducible form of heat shock protein 70 (Hsp70) has been shown to reduce polyglutamine-induced toxicity. To investigate if overexpression of Hsp70 can affect disease progression in a mouse model of HD, we crossed R6/2 mice, expressing exon 1 of the $H D$ gene with an expanded CAG repeat, with mice overexpressing Hsp70 (both types of transgenic mice were of the CBAxC57BL/6 strain). The resulting R6/2-Hsp70 transgenics exhibited 5- to 15-fold increases in Hsp70 expression in neocortical, hippocampal and basal ganglia regions. This correlated with a delayed loss of body weight compared to R6/2 mice. However, the number or size of nuclear inclusions, the loss of brain weight, reduction of striatal volume, reduction in size of striatal projection neurons, downregulation of DARPP-32, development of paw clasping phenotype and early death of the mice were not affected by Hsp70 overexpression. Interestingly, the polyglutamine protein affected the potential rescuing agent, because in older R6/2-Hsp70 mice a large proportion of the Hsp70 protein was sequestrated in nuclear inclusions.
\end{abstract}

\section{Introduction}

Huntington's disease (HD) is an autosomal dominantly inherited neurodegenerative disorder manifested by chorea, personality changes and dementia. Neuronal loss occurs primarily in the striatum, although at later stages other brain regions are also affected [44]. The disease mutation

\footnotetext{
*Corresponding author. Tel.: +46-46-222-0529; fax: +46-46-2220531 .

E-mail addresses: oskar.hansson@mphy.lu.se (O. Hansson), patrik.brundin@neurol.lu.se (P. Brundin).

${ }^{1}$ Co-corresponding author.
}

is an expansion of a CAG trinucleotide polyglutaminecoding repeat in exon 1 of the huntingtin gene [38]. Normally, 6-34 CAG repeats are present in this locus, while more than 35 are found in patients with HD [17]. The mechanism through which mutant huntingtin mediates neurotoxicity is unknown. It has been suggested that the disease mutation results in a misfolding (conformational shift) of huntingtin [40], which may cause abnormal interactions with other proteins or between mutant huntingtin molecules (for review see: [39]). Such altered interactions may explain the nuclear huntingtin-containing inclusions found in the brains of human HD patients [12].

A useful tool to investigate the unknown HD pathogenic mechanism is the $\mathrm{R} 6 / 2$ transgenic mouse model that 
expresses exon 1 of a human $H D$ gene with $150 \mathrm{CAG}$ trinucleotide repeats [27]. These mice exhibit some key features of HD, including reduced brain and body weight, neuronal shrinkage and condensation [15,41], aggregates/ inclusions containing N-terminal huntingtin [11], and reduced levels of striatal dopamine receptors [5] and dopamine signalling proteins [3]. The role of protein aggregate inclusions in the pathogenesis of HD is an issue of intensive research (for review see, e.g. Refs. $[39,46]$ ). Aggregates of $\mathrm{N}$-terminal mutant huntingtin sequester proteasomal components [21], and aggregates of mutant huntingtin can inhibit the proteasome in cultured nonneuronal cells and thereby disturb general cellular protein turnover [2]. However, in a murine model of another polyglutamine disease, spinocerebellar ataxia 1 (SCA1) [9] and a cellular model of HD [33], mutations of ubiquitinligase, that reduce the formation of aggregates, actually increase the toxicity of the mutant proteins. This suggests that aggregates of polyglutamine-containing proteins can be protective and that inhibition of ubiquitin-proteasome pathway of protein degradation can be detrimental $[9,33]$. Molecular chaperones, including heat shock proteins (Hsp), prevent misfolding and aggregation of newly synthesized mutant proteins and stress-denatured proteins, and thereby reduce the burden on the ubiquitin-proteasome pathway $[16,23]$. Understanding whether and how molecular chaperones influenc aggregation and toxicity of mutant huntingtin may help to clarify the role of protein inclusions in the human disease [35].

Molecular chaperones, including heat shock proteins (Hsp) 40 and 70, co-localize with neuronal inclusion in several polyglutamine disorders $[6,8,36,49]$, and mutations in Hsp70 enhance polyglutamine-induced pathogenesis in vivo in Drosophila [14]. In a number of studies using in vitro transfected cell line models of polyglutamine disorders, overexpression of Hsp40 and/or Hsp70 reduces the formation of inclusions and/or the number of dying cells $[6,8,20,25,29]$. Similarly expression of the yeast chaperone Hsp104 in C. elegans reduces both toxicity and aggregate formation due to expression of a protein with an expanded polyglutamine stretch [32]. Overexpression of Hsp70 in Drosophila suppresses neurodegeneration, however, without affecting the formation of neuronal inclusions [47]. Similarly, overexpression of Hsp70 in a transgenic model of SCA1 has been reported to retard development of a neurological phenotype and to inhibit the development of neuronal pathology without affecting the formation of neuronal intranuclear aggregates of ataxin-1 [10]. The challenge now is to determine whether the molecular chaperone Hsp70, at overexpression levels that might be attainable through therapeutic intervention, can protect neurons in vivo in transgenic HD mice, and if the aggregation of mutant huntingtin is reduced. We have addressed this question by overexpressing Hsp70 in the R6/2 line of transgenic mice that expresses exon 1 of the $H D$ gene.

\section{Materials and methods}

\section{Animals}

Heterozygous transgenic R6/2 males of CBA $\times$ C57BL/ 6 strain were purchased from Jackson Laboratories (Bar Harbor, Maine, USA) and maintained by back-crossing carrier males with $\mathrm{CBA} \times \mathrm{C} 57 \mathrm{BL} / 6 \mathrm{~F} 1$ females. Transgenic mice of the $\mathrm{CBA} \times \mathrm{C} 57 \mathrm{BL} / 6$ strain overexpressing human inducible Hsp70 under the control of the human beta-actin promotor [1] were kindly provided by Dr G.N. Pagoulatos, University of Ionnina, Greece. To generate R6/2 mice overexpressing Hsp70, heterozygous transgenic Hsp70 females were mated with heterozygous R6/2 males. The experimental procedures were approved by the ethical committee at Lund University, the animals were handled according to the animal protection act of the Swedish Government. R6/2 and Hsp70 mice were genotyped using polymerase chain reaction assays as previously described $[1,27]$.

\section{Immunohistochemistry}

Free floatin sections were immunostained for either N-terminal huntingtin (EM48 antiserum; 1:1000; kindly provided by Dr Xiao-Jiang Li), Hsp70 (1:200; SPA812; Stressgene, Gothenburg, Sweden), DARPP-32 (dopamineand cyclic AMP-regulated phosphoprotein with a molecular weight of $32 \mathrm{kDa}$ ) (1:2000; Calbiochem, San Diego, USA) or neuron-specifi enolase (1:500; NeuN, Chemicon, Sweden). Sections stained with the EM48 antibody were firs subjected to an antigen retrieval method as previously described [22]. The sections were treated with 3\% hydrogen peroxide $/ 10 \%$ methanol $/ 0.1 \mathrm{M}$ phosphate buffered saline and then incubated with $10 \%$ serum $/ 0.3 \%$ Triton $\mathrm{X}-100$ for $1 \mathrm{~h}$ at room temperature, followed by a reaction with the primary antibody for $48 \mathrm{~h}$ at $4{ }^{\circ} \mathrm{C}$. For light microscopy, sections were incubated with a biotinylated secondary antibody (1:200) for $2 \mathrm{~h}$ and bound antibody was visualized using the $\mathrm{ABC}$ system (Vectastain $\mathrm{ABC}$ Kit, Vector, Sweden), with 3,3'-diaminobenzidine as chromogen. For confocal microscopy, sections were incubated with an Alexa 568-conjugated secondary antibody (Molecular Probes, Eugene, USA) and Vectashield (Vector) was used to reduce photo bleaching.

When comparing the expression of Hsp70 in the brain of the different transgenic mice, all sections were processed for immunohistochemistry at the same time. In addition, the staining protocol was repeated one time with the same results obtained. Confocal pictures were generated using a Bio-Rad MRC 1024 confocal microscope with the same settings (laser power, gain, etc.) for all pictures.

\section{Stereology}

The numbers of nuclear inclusions in the striatum, 
hippocampus or cortex were estimated on blind-coded sections by using the unbiased stereology optical fractionater, as previously described [19]. This sampling technique is not affected by tissue volume changes and does not require reference volume determination and is considered to provide the most accurate estimates of cell numbers [7]. Sampling was performed using the CAST-Grid system (Olympus Denmark A/S, Albertslund, Denmark). It is composed of an Olympus BX50 microscope, an $X-Y$ motor stage run by a computer, and a microcater (Heidenhain, ND 281) connected to the stage. The same system was used to determine the size of the striatum and to investigate the diameter of hippocampal neurons and striatal DARPP-32 positive neurons. Around 150 neurons in each mouse were investigated to obtain a mean value of the diameter of the striatal and hippocampal neurons in that mouse.

\section{Western blotting}

Whole brains were frozen with liquid nitrogen within 60 $\mathrm{s}$ after decapitation and striatum, hippocampus and cortex were dissected out at $-17^{\circ} \mathrm{C}$ and stored at $-80^{\circ} \mathrm{C}$ until analysis. The brain tissue pieces were lysed in Tris-lysis buffer ( $20 \mathrm{mM}$ Tris- $\mathrm{HCl}$ (pH 7.7), $250 \mathrm{mM} \mathrm{NaCl}, 3 \mathrm{mM}$ EDTA, $0.5 \% \mathrm{NP}-40$ and $3 \mathrm{mM}$ EGTA) for $30 \mathrm{~min}$ at $4{ }^{\circ} \mathrm{C}$. Equal amounts of protein were separated by $8 \%$ SDS/ PAGE ( $0.6 \mathrm{mg}$ of brain tissue per lane) and transferred to nitrocellulose for immunodetection. Mouse $\mathrm{mAb}$ against Hsp70 (2H9), Hsc70 (N69A) (kindly provided by Boris Margulis, Russian Academy of Sciences, St. Petersburg) and glyceraldehyde 3-phosphate dehydrogenase were used as primary antibodies.

\section{Paw clasping}

Mice of the R6/2 strain exhibit a special paw clasping phenotype when suspended by the tail [27]. Evaluation of the clasping phenotype has previously been used to study the disease progression in transgenic HD mice $[31,42,43,48]$. The mice were suspended by the tail for 180 $\mathrm{s}$. The clasping phenotype was rated on a scale from 0 to 2 , where 0 represents no clasping behavior; a score of 1 means that the hind paws touch each other for at least $1 \mathrm{~s}$, and the maximal score of 2 means that hind paws clasp for $5 \mathrm{~s}$ or more.

\section{Statistics}

Statistical comparisons of the dependent factors were undertaken by one- or two-factor analyses of variance (ANOVA) using the Statview 5.4 package (Abacus Concepts, Berkley, CA, USA). When the main effect was significant Bonferroni-Dunn's post hoc test was used to correct for multiple analyses. Ordinal data (Fig. 6A) were analyzed using Mann-Whitney $U$-tests. Data are presented as means \pm S.D.

\section{Results}

To generate R6/2 mice overexpressing human inducible Hsp70, heterozygous transgenic Hsp70 females were mated with heterozygous R6/2 males. Around $25 \%$ of the offspring consisted of controls, Hsp70 transgenics, R6/2 transgenics and Hsp70-R6/2 double transgenics, respectively. Importantly, both the R6/2 mice and Hsp70 transgenics are of the same genetic background (strain: CBA $\times$ C57BL/6), reducing the risk that other genes than the transgene in the Hsp70 overexpressing mice will affect the disease phenotype of the R6/2 mice overexpressing Hsp70 (Hsp70-R6/2 transgenics). Nevertheless, the different types of mice could still carry different combinations of $\mathrm{CBA} \times \mathrm{C} 57 \mathrm{BL} / 6$ allels. The selection of allels is random for most of the genome, however, for the regions around the two transgenes it is fixed Therefore, allels linked to the transgenes may have phenotypic consequences which may then be incorrectly attributed to the transgene (see Ref. [34]).

\section{Expression of Hsp 70 in the brain of mice of different genotypes}

Immunoblot analysis of protein samples prepared from various brain parts of 7-week-old mice revealed that Hsp70 protein was expressed at around 5-15 times higher level in hippocampus, striatum, cortex (Fig. 1A) and in the whole brain (Fig. 1B) of Hsp70 transgenics and Hsp70-R6/2 transgenics than in controls. Immunohistochemistry confirme the high expression of Hsp70 in hippocampus, striatum and cortex in Hsp70 transgenics and Hsp70-R6/2 transgenics (Fig. 1C-N). In R6/2 and Hsp70-R6/2 transgenics some of the Hsp70 protein was localized in inclusions (Fig. 1E,F,I,J,M,N) and the Hsp70 protein expression in the cytoplasm appeared reduced in many of the neurons with a clear localization of Hsp70 in inclusions.

\section{Similar number and size of nuclear inclusions in Hsp 70-R6/2 and R6/2 mice}

R6/2 mice exhibit a widespread formation of nuclear inclusions containing huntingtin, especially in cortex, striatum and hippocampus [11]. The number of neurons with huntingtin inclusions in striatum, CA1 area of hippocampus, dentate gyrus and cortex of 7 -week-old R6/2 mice and Hsp70-R6/2 mice were evaluated. We found no difference in the number of neurons with huntingtin inclusions between R6/2 mice and Hsp70-R6/2 mice (Fig. $2 \mathrm{~A}-\mathrm{K})$. In addition, we found no difference in the size or 

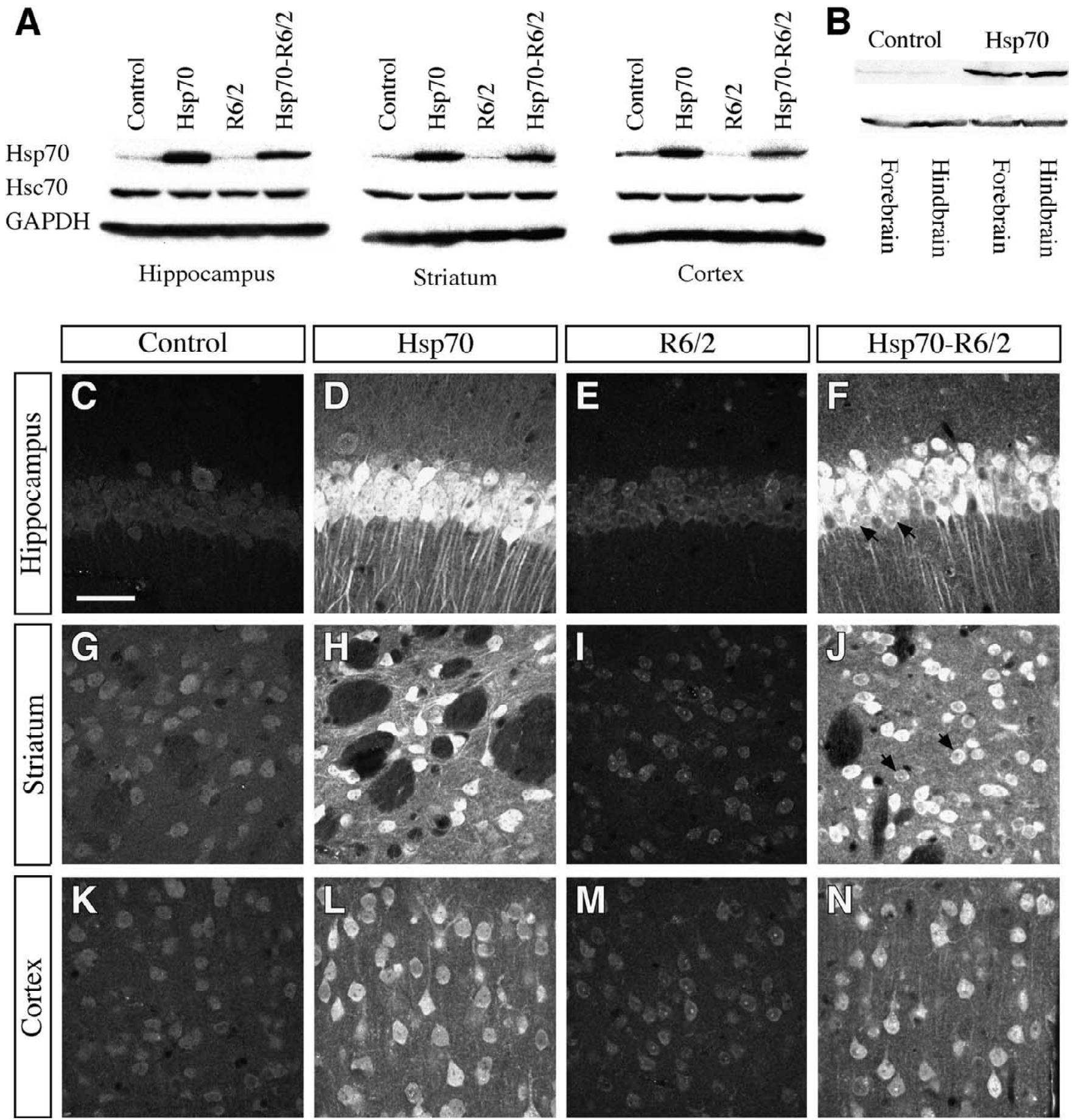

Fig. 1. Expression of Hsp70 protein in 7-week-old mice was evaluated with western blotting (A, B) and immunohistochemistry (C-N). Western blotting revealed increased expression of Hsp70 protein in the whole brain of Hsp70 overexpressing mice (B) and in cortex, striatum and hippocampus of Hsp70 and Hsp70-R6/2 mice when compared to control and R6/2 mice (A). Constitutively expressed heat shock protein 70 (Hsc70) and GAPDH were used as loading controls (A, B). Similar results were obtained when brain sections from hippocampus (C-F), striatum (G-J), and cortex (K-N) of control (C, G, $\mathrm{K})$, Hsp (D, H, L), R6/2 (E, I, M) and Hsp70-R6/2 (F, J, N) mice were processed for Hsp70 immunohistochemistry and evaluated with confocal microscopy. Note the localization of Hsp70 protein in inclusions in R6/2 and Hsp70-R6/2 mice. The localisation of Hsp70 immunoreactivity to the inclusions, and the concomitant reduction of Hsp70 levels in the cytoplasm, is particularly evident in panels $\mathrm{F}$ and $\mathrm{J}$ (examples of cells illustrated by arrows). $n=4-8$ per group [Bar=40 $\mu \mathrm{m}]$. 

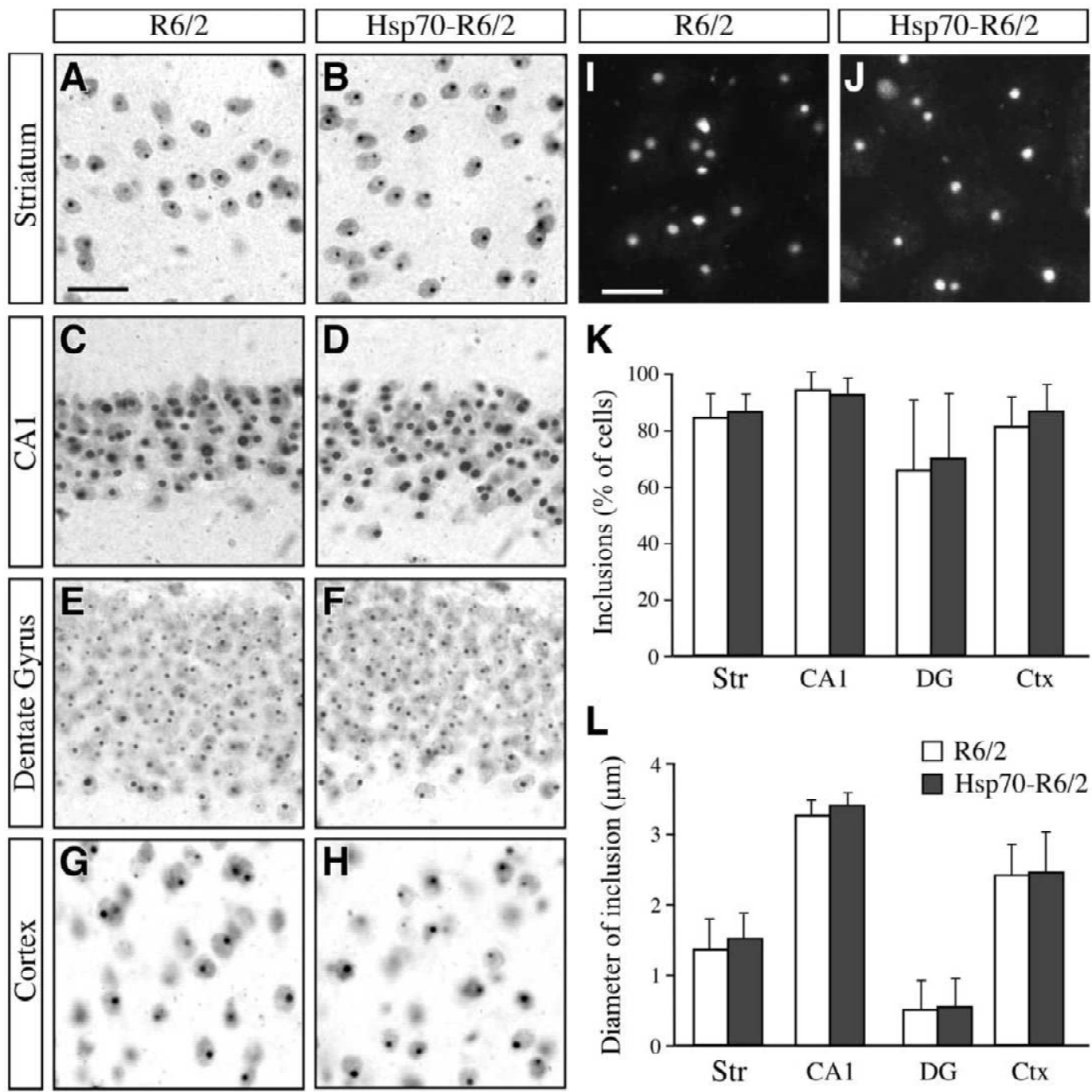

Fig. 2. The number and size of nuclear inclusions in 7-week-old R6/2 and Hsp70-R6/2 mice were evaluated using light microscopy (A-H) and confocal microscopy (I, J). Sections from striatum (A, B, I, J), CA1 (C, D), dentate gyrus (E, F), and cortex (G, H) were processed for EM48 immunohistochemistry to detect N-terminal huntingtin. Quantificatio of the percentage of cell with nuclear inclusions $(\mathrm{K})$ and the size of the inclusions (L) revealed no difference between R6/2 and Hsp70-R6/2 mice. Data are presented as mean \pm S.D. ( $n=6-8$ per group). [Bars $=25 \mu \mathrm{m}(\mathrm{A}-\mathrm{H})$, and $10 \mu \mathrm{m}$ $(\mathrm{I}-\mathrm{J})]$.

morphology of the huntingtin inclusions between R6/2 mice and Hsp70-R6/2 mice (Fig. 2A-J,L).

\section{Hsp 70 expression delayed the reduction of body} weight in R6/2 mice, but had no effect on brain weight

R6/2 mice progressively loose body and brain weight from around 7 weeks of age [11,27]. We investigated the body weight of the mice at 4, 7, 9, 11 and 13 weeks of age. Both R6/2 and Hsp70-R6/2 mice had normal body weight at 4 weeks of age (data not shown). There was a difference in body weight between R6/2 and Hsp70-R6/2 at 7 weeks of age $(P<0.0001$, Bonferroni-Dunn's post hoc test), but not at later ages (Fig. 3A). There was no difference in body weight between control mice and Hsp70 mice (98 $\pm 7 \%$ of control). Brain weight was investigated at 7 and 14 weeks of age and there was no difference between R6/2 and Hsp70-R6/2 mice (Fig. 3B).

\section{Similar neuropathology in striatum of $R 6 / 2$ and R6/2-Hsp70 mice}

The size of the striatum [18], and the size of the neurons in striatum [15] is reduced in R6 HD mice. We found that the size of striatum and the diameter of medium spiny projection neurons (DARPP-32 immunopositive) were equally decreased in 7-week-old R6/2 and Hsp70-R6/2 mice (Fig. 4A,B). In addition, we confirme earlier data [3] showing that the dopamine signaling protein DARPP32 is downregulated in the striatum of 6- to 8-week-old R6/2 mice. Importantly, the levels of DARPP-32 were reduced to the same extent in Hsp70-R6/2 mice (Fig. 4C). 

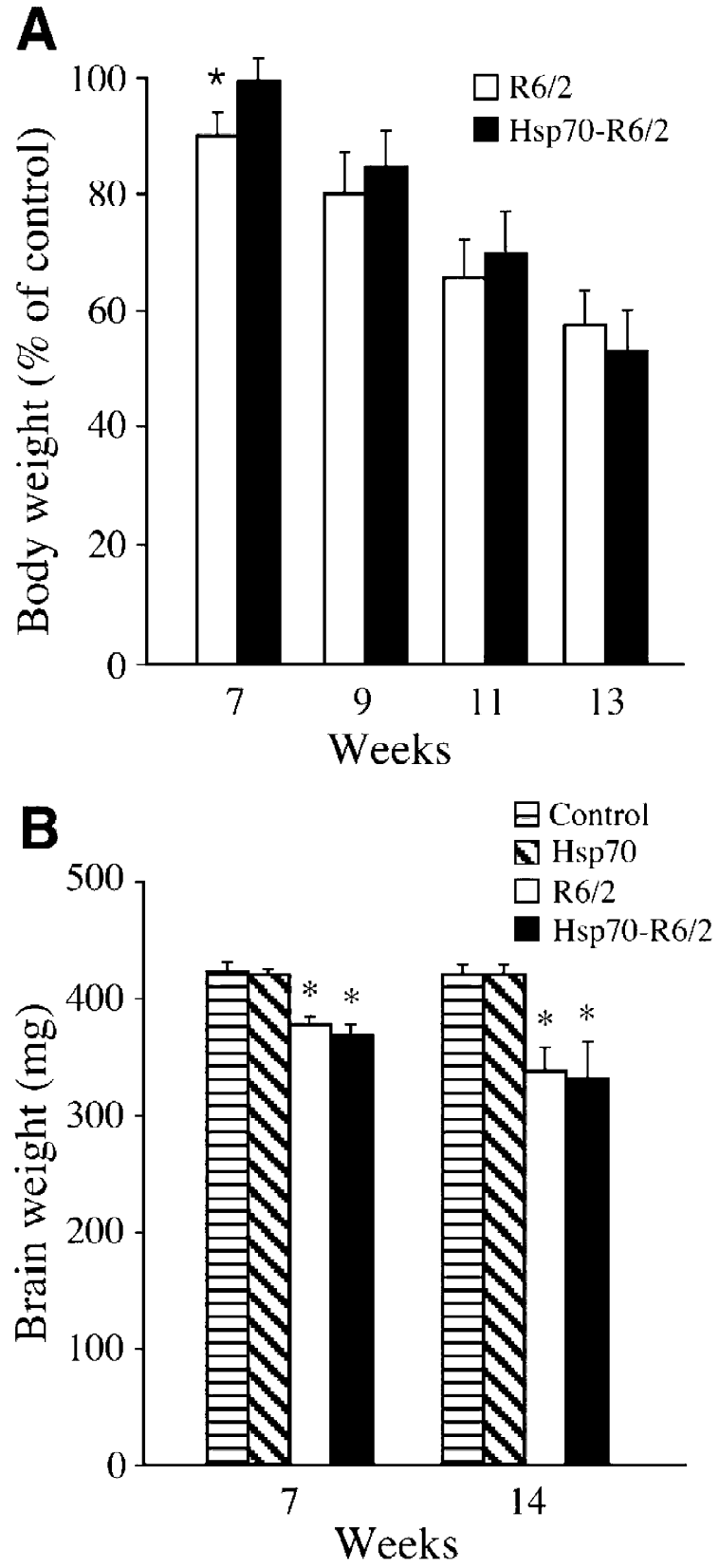

Fig. 3. Measurement of body weight of R6/2 and Hsp70-R6/2 mice revealed a significan difference at 7 weeks of age (A). The data are expressed as percentage of littermate controls (mean \pm S.D.). *Significantl different from R6/2 mice, $P<0.0001$, Bonferroni Dunn's post hoc test. ( $n=25-26$ for 7-week-old mice and $n=10-15$ for 9 - to 13-week-old mice). Panel (B) reveals that brain weight is reduced to the same degree in R6/2 and Hsp70-R6/2 mice at 7 and 14 weeks of age. *Significantl different from control mice, $P<0.0001$, Bonferroni Dunn's post hoc test. Data are presented as mean \pm S.D. ( $n=6-10$ per group).

\section{Effects of Hsp 70 on hippocampal alterations}

In the hippocampal CA1 area, we found that neurons in both R6/1 and Hsp70-R6/2 mice exhibited darkened cytoplasm in Cresyl Violet stained sections, indicative of cellular condensation (Fig. 5A-D). However, only neurons in $\mathrm{R} 6 / 2$, but not in Hsp70-R6/2 double transgenic mice,
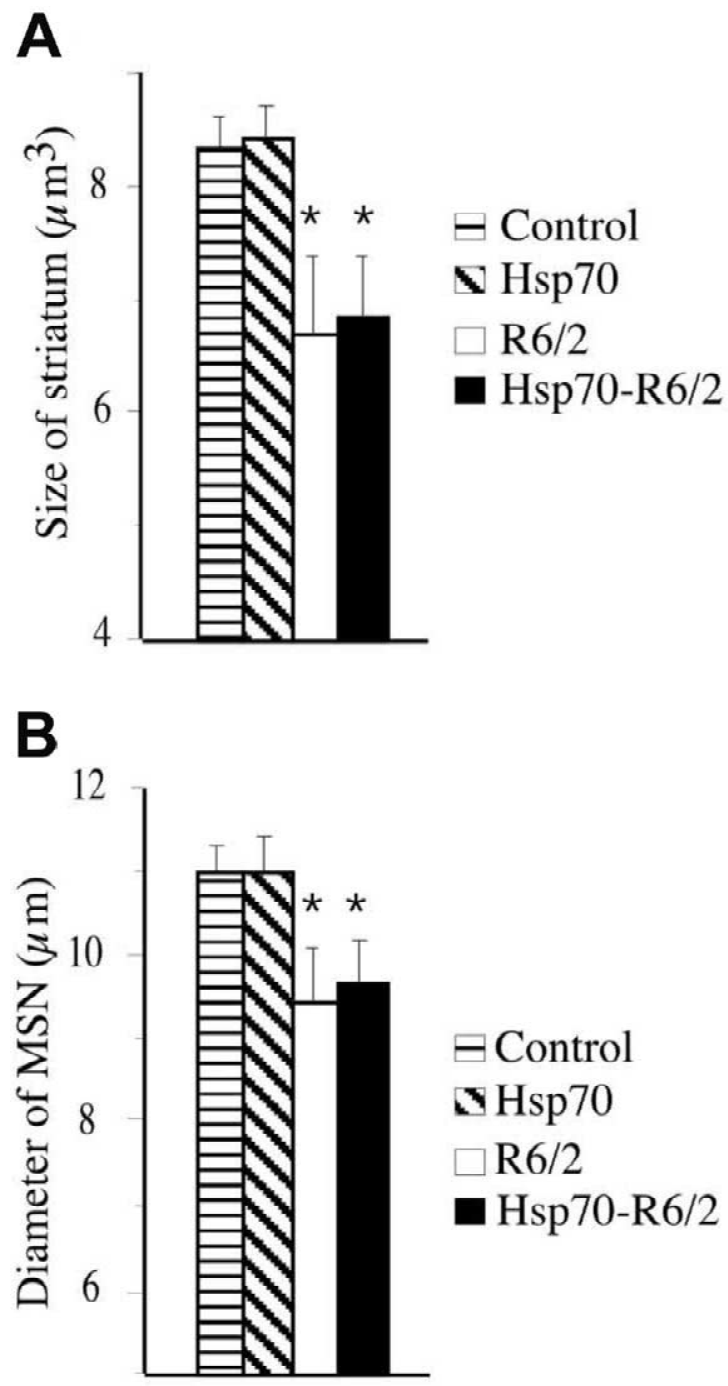

C

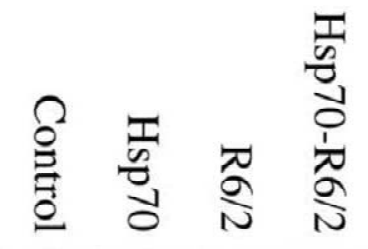

DARPP-32

\section{Hsc70}

Fig. 4. Quantificatio of the volume of the striatum (A) and the diameter of medium sized spiny projection neurons (MSN) (DARPP-32 immunopositive) (B) revealed that both parameters are decreased to the same degree in 7-week-old R6/2 and Hsp70-R6/2 mice. *Significan from control mice, $P<0.001$, Bonferroni Dunn's post hoc test. Data are presented as mean \pm S.D. ( $n=5$ per group). (C), Western blotting revealed decreased expression levels of DARPP-32 in the striatum of both R6/2 and Hsp70-R6/2 mice. Constitutively expressed heat shock protein 70 (Hsc70) were used as a loading control.

displayed significantl smaller cell body diameters compared to wild-type neurons (Fig. 5E). Importantly, the difference between R6/2 and Hsp70-R6/2 hippocampal neurons was not statistically significan (Fig. 5E). 


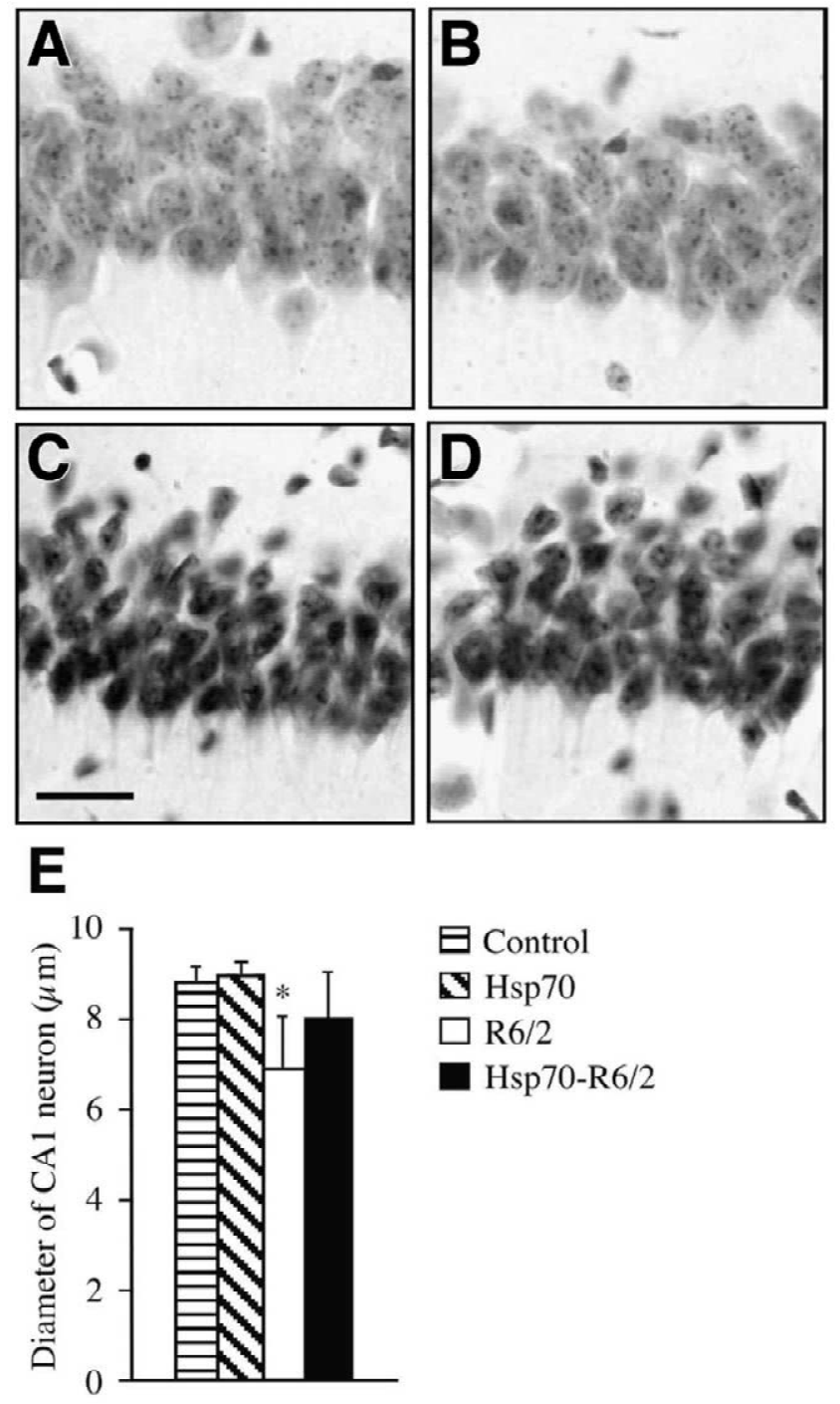

Fig. 5. Photomicrographs of Cresyl violet-stained hippocampal sections revealed condensation of CA1 neurons in both 7-week-old R6/2 (C) and Hsp70-R6/2 (D) mice when compared to control (A) and Hsp70 (B) mice. However, when the diameter of the CA1 neurons were quantified only neurons in R6/2 but not in Hsp70-R6/2 mice were significantl different from control (E). *Significan from control mice, $P<0.002$, Bonferroni Dunn's post hoc test. Data are presented as mean \pm S.D. $(n=5$ per group). [Bar=15 $\mu \mathrm{m}]$.

\section{Clasping phenotype and the survival of R6/2 mice} are not affected by overexpression of $H s p 70$

HD mice of the R6/2 line exhibit a special paw clasping phenotype when suspended by the tail [27]. Some of the R6/2 and Hsp70-R6/2 mice exhibited a clasping phenotype at 5 weeks of age and all mice in both groups showed a clasping phenotype at 11 weeks of age (Fig. 6A). There was no difference between R6/2 and Hsp70-R6/2 mice at any age $(P>0.10$, Mann-Whitney $U$-test $)$. In addition, there was no difference in the survival of $\mathrm{R} 6 / 2$ and Hsp70-R6/2 mice (Fig. 6B).

\section{Change of intracellular localization of $\mathrm{Hsp} 70 \mathrm{in}$ 11-week-old Hsp 70-R6/2 mice}

We found that the cytoplasmic levels of Hsp70 protein in neurons, especially in the hippocampus, were signifi cantly lower in Hsp70-R6/2 mice at the age of 11 weeks than in 11-week-old Hsp70 mice (Fig. 7A,B). This was in contrast to 7-week-old mice which did not display a difference between Hsp70 mice and the double transgenic R6/2-Hsp70 mice (Fig. 1). Presumably this is the result of a redistribution of the $\mathrm{Hsp} 70$ protein in the older mice, as in many neurons it appeared to be mainly localized to the nuclear inclusions. The localization of a neuronal marker NeuN was not altered suggesting that the translocation is specifi for Hsp70 possibly as a consequence of it being sequestered into the inclusions (Fig. 7C,D).

\section{Discussion}

Hsp70 is a molecular chaperone that can prevent misfolding and assist refolding of damaged and mutant proteins. We hypothesized that overexpression of Hsp70 would retard pathogenesis in a transgenic mouse model of polyglutamine disease. We generated Hsp70-R6/2 double transgenic mice, which were found to overexpress Hsp70 widely throughout the brain. Initially, at 7 weeks of age, Hsp70 was present throughout the cytoplasm of brain cells in all the regions we examined, although in some neurons the Hsp70 was partially sequestered into nuclear aggregates. In both R6/1 and R6/2 mice, some heat shock protein family members (e.g. Hdj-2 and Hsc70) have previously been found to redistribute with increasing age, and increasingly co-localize with intranuclear inclusions formed by truncated mutant huntingtin [20]. We found here, using immunohistochemistry, that Hsp70 immunoreactivity in Hsp70-R6/2 double transgenic mice often appeared in puncta with a nuclear localization, and by 11 weeks of age the puncta were particularly distinct and the levels of cytoplasmic Hsp70 were clearly reduced compared to at 7 weeks. Previous studies have demonstrated that neuronal inclusions containing huntingtin can recruit several proteins, including heat shock proteins, ubiquitin, proteasome components, $\mathrm{p} 53$, cytoskeletal proteins, alphasynuclein, etc. [21,37,45]. In striatal neurons of Hsp70-R6/ 2 mice, the apparent level of immunoreactivity for another protein, neuron specifi enolase, did not change, indicating that nuclear aggregates preferentially attract certain protein families.

As a parameter for the behavioral disease phenotype we chose a paw-clasping assay. Abnormal paw-clasping behavior has been shown to be related to striatal dysfunction [13] and it is considered a relevant indicator of neuropathology in transgenic mice expressing expanded CAG repeats $[27,31,42,43,48]$. Thus, it has been found to develop in several transgenic models of HD [27,31,48], respond to treatments in the R6/2 transgenic mice $[42,43]$ 


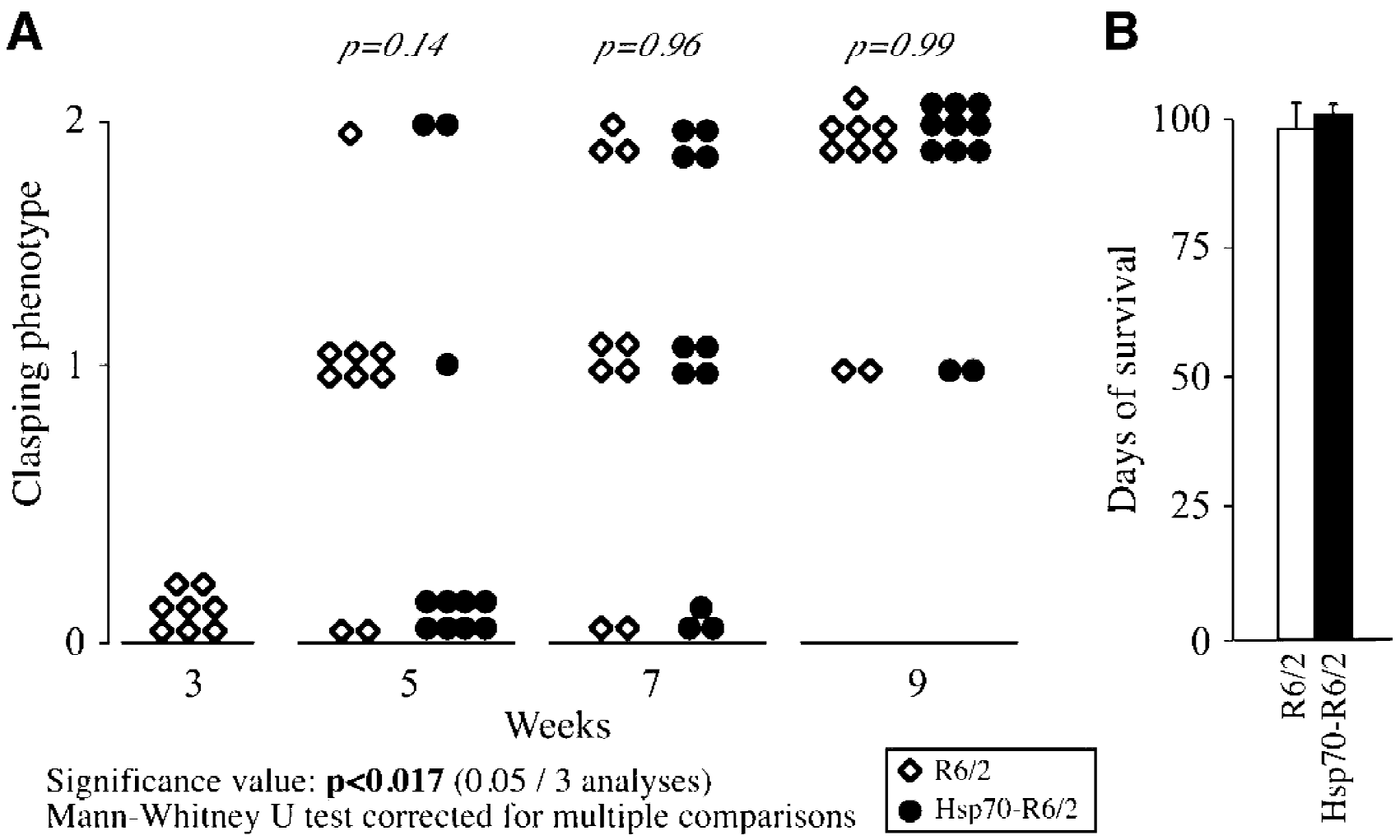

Fig. 6. The clasping phenotype of R6/2 and Hsp70-R6/2 mice were evaluated at different ages. The clasping phenotype was rated 0-2 (see the Materials and methods section) (A). Some of the mice in both groups showed a clasping phenotype already at 5 weeks of age. Statistical analyses revealed no statistically significan difference between R6/2 and Hsp70-R6/2 at any age ( $P>0.01$, Mann-Whitney $U$-test). Panel (B), depicts that there is no difference in the survival of R6/2 and Hsp70-R6/2 mice. ( $n=10$ for HD and $n=6$ for Hsp70-R6/2 mice).

and is normalized in an inducible transgenic model of HD after the transgene is turned off [48]. We did not observe a significan difference in the development of pathological paw clasping behavior between Hsp70-R6/2 and R6/2 mice.

In addition we examined a wide panel of histopathological changes. Also here, Hsp70 overexpression had hardly any effects on the disease phenotype. The only neuropathological feature significantl mitigated by the overexpression of Hsp70 in the R6/2 mice was the atrophy of CA1 hippocampal pyramidal neurons. At 7 weeks of age the mean cell soma diameter of Cresyl Violet stained CA1 neurons was reduced by around $25 \%$ in R6/2 mice compared to wild-type, and this atrophy was only half as severe in R6/2 mice overexpressing Hsp70.

In summary, our study does not provide strong evidence that Hsp70 overexpression can retard progression of polyglutamine-induced disease in the R6/2 transgenic model of HD. In contrast, several earlier in vitro studies have provided evidence that overexpression of different heat shock protein family members significantl abrogate other forms of polyglutamine-mediated toxicity, and in some cases reduce the formation of aggregates of misfolded proteins $[4,6,8,20,25,26,29,36,50]$. When comparing these results with those of the present study, it is necessary to consider the class of heat shock protein overexpressed, the selection of cell model, and the outcome parameters monitored. In addition to the cell culture models, there is also ample evidence that heat shock proteins can retard disease progression in animal models of polyglutamineinduced disease. For example, disruption of the chaperone functions of heat shock proteins by mutations has been found to increase ataxin-1 toxicity in Drosophila melanogaster [14] and heat shock protein overexpression mitigates polyglutamine-induced pathology in Drosophila $[24,47]$. Finally, in a recent study, Hsp70 overexpression was found to delay the development of motor coordination problems on the rotarod in transgenic mice expressing mutant ataxin-1 [10]. Taken together, these studies suggest that overexpression of heat shock proteins can mitigate the development of polyglutamine-mediated neuropathology under certain conditions. However, the mechanism of action remains unclear, because the abrogation of toxicity was not accompanied by a reduced formation of protein aggregates in many of the models studied.

In view of the results of previous studies suggesting that heat shock proteins might take the role of guardians, protecting cells from toxicity due to mutant huntingtin, it is interesting to speculate why Hsp70 overexpression did not reduce HD pathology in our mouse model. The protective effects of Hsp70 may rely on an intricate balance between protein refolding and aggregate formation, where over- 


\section{Hsp70}
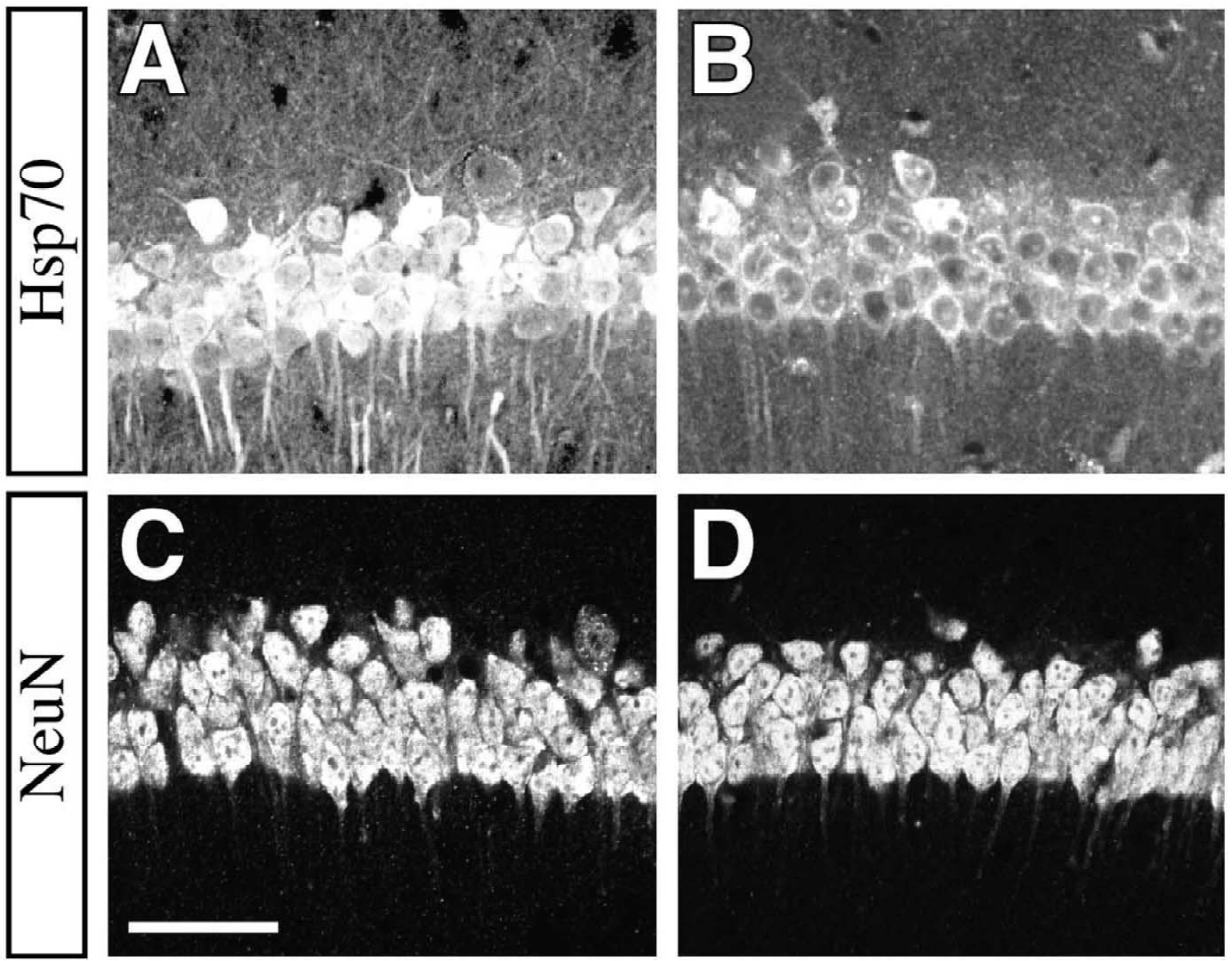

\section{Hsp70-R6/2}

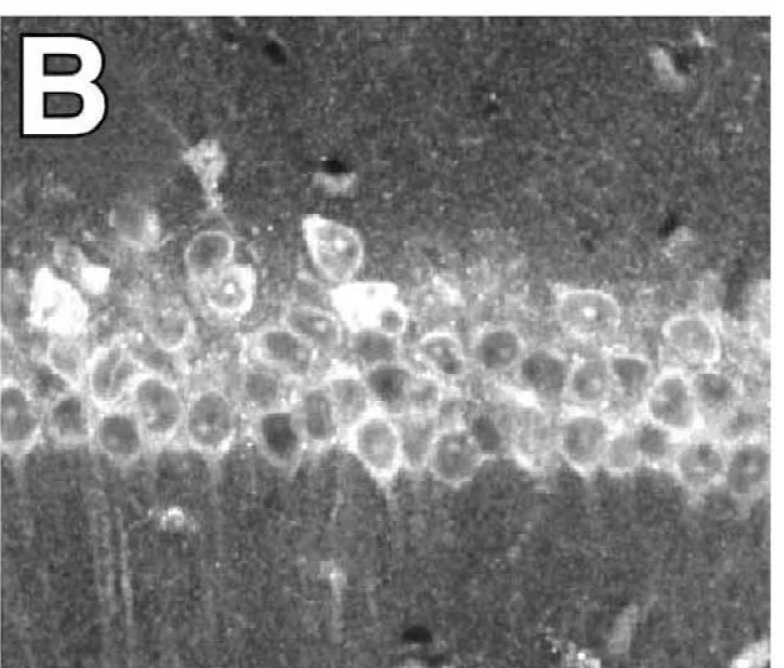

Fig. 7. Confocal photomicrographs of hippocampal sections stained for Hsp70 (A, B) and NeuN (C, D) from 11-week-old Hsp (A, C) and Hsp70-R6/2 (B, D) mice. The expression of Hsp70 in CA1 neurons from 11-week-old Hsp70-R6/2 transgenic mice is reduced in the cytoplasm when compared to Hsp70 overexpressing transgenic mice. However, the expression of NeuN is unchanged ( $n=2$ per group). [Bar $=35 \mu \mathrm{m}]$.

expression of Hsp70 can delay polyglutamine pathology only up to a certain point. The relative efficac of Hsp70 may also depend on the level of expression of the mutant protein, the size of the polyglutamine tract and the protein context in which it is expressed. The R6/2 model of HD expresses the $\mathrm{N}$-terminal part of mutant huntingtin with around 150 glutamine residues, and is known to exhibit neuronal nuclear inclusions relatively early, maybe because the truncated protein does not require further proteolytic cleavage $[11,28]$. In contrast, the SCA1 model employed by Cummings and coworkers expresses the full length mutant ataxin-1 with only 82 CAG repeats. Thus, the discrepancy in the magnitude of observed effects of Hsp70 overexpression in these two transgenic models of polyglutamine disease may well be related to differences in 
to peptides is dependant on Hsp40-enhanced ATP hydrolysis [30]. As neuronal aggregates of $\mathrm{N}$-terminal mutant huntingtin have been shown to recruit the Hsp40 family member Hdj-2 in R6/1 and R6/2 mice [20], it is possible that there is a relative shortage of Hsp40 family members in R6/2 mice, making the overexpression of Hsp70 inefficient Earlier studies have suggested that coexpression of Hsp40 together with Hsp70 may be necessary to efficientl counteract the effects of expanded polyglutamine stretches $[25,29]$. Therefore, it would be interesting for future studies to evaluate the effects of upregulation of several chaperons, including Hsp70 and Hsp40, in R6/2 mice.

In conclusion, the present study highlights that there may be important differences between cell and animal models of slow neurodegenerative diseases. An induction of increased levels of molecular chaperones has been suggested as a therapeutic strategy for HD [46], but the current results indicate that a deeper understanding of the effects and kinetics of heat shock protein mediated reactions are needed before such strategies should be seriously considered for clinical trials.

\section{Acknowledgements}

We acknowledge the technical assistance of Birgit Haraldsson, Britt Lindberg, Elsy Ling, Bengt Mattsson and Ingrid Fosser Larsen. This study was supported by grants from Swedish and Danish Medical Research Councils, Swedish Association of the Neurologically Handicapped and Danish Cancer Society. We acknowledge fruitful discussions made during meetings of The Nordic Stress Response Network and The European Union concerted action consortium 'Early pathogenetic markers for Slow Neurodegenerative Disease' (EPSND, QLK6-CT-200000384). O.H. was supported by the Swedish National Network in Neuroscience and R.F.C. by FAPESP.

\section{References}

[1] C.E. Angelidis, C. Nova, I. Lazaridis, D. Kontoyiannis, G. Kollias, G.N. Pagoulatos, Overexpression of HSP70 in transgenic mice results in increased cell thermotolerance, Transgenics 2 (1996) $111-117$.

[2] N.F. Bence, R.M. Sampat, R.R. Kopito, Impairment of the ubiquitin-proteasome system by protein aggregation, Science 292 (2001) 1552-1555.

[3] J.A. Bibb, Z. Yan, P. Svenningsson, G.L. Snyder, V.A. Pieribone, A. Horiuchi, A.C. Nairn, A. Messer, P. Greengard, Severe deficiencie in dopamine signaling in presymptomatic Huntington's disease mice, Proc. Natl. Acad. Sci. USA 97 (2000) 6809-6814.

[4] J. Carmichael, J. Chatellier, A. Woolfson, C. Milstein, A.R. Fersht, D.C. Rubinsztein, Bacterial and yeast chaperones reduce both aggregate formation and cell death in mammalian cell models of Huntington's disease, Proc. Natl. Acad. Sci. USA 97 (2000) 97019705.
[5] J.H. Cha, C.M. Kosinski, J.A. Kerner, S.A. Alsdorf, L. Mangiarini, S.W. Davies, J.B. Penney, G.P. Bates, A.B. Young, Altered brain neurotransmitter receptors in transgenic mice expressing a portion of an abnormal human huntington disease gene, Proc. Natl. Acad. Sci. USA. 95 (1998) 6480-6485.

[6] Y. Chai, S.L. Koppenhafer, N.M. Bonini, H.L. Paulson, Analysis of the role of heat shock protein (Hsp) molecular chaperones in polyglutamine disease, J. Neurosci. 19 (1999) 10338-10347.

[7] R.E. Coggeshall, H.A. Lekan, Methods for determining numbers of cells and synapses: a case for more uniform standards of review, J. Comp. Neurol. 364 (1996) 6-15.

[8] C.J. Cummings, M.A. Mancini, B. Antalffy, D.B. DeFranco, H.T. Orr, H.Y. Zoghbi, Chaperone suppression of aggregation and altered subcellular proteasome localization imply protein misfolding in SCA1, Nat. Genet. 19 (1998) 148-154.

[9] C.J. Cummings, E. Reinstein, Y. Sun, B. Antalffy, Y. Jiang, A. Ciechanover, H.T. Orr, A.L. Beaudet, H.Y. Zoghbi, Mutation of the E6-AP ubiquitin ligase reduces nuclear inclusion frequency while accelerating polyglutamine-induced pathology in SCA1 mice, Neuron 24 (1999) 879-892.

[10] C.J. Cummings, Y. Sun, P. Opal, B. Antalffy, R. Mestril, H.T. Orr, W.H. Dillmann, H.Y. Zoghbi, Over-expression of inducible HSP70 chaperone suppresses neuropathology and improves motor function in SCA1 mice, Hum. Mol. Genet. 10 (2001) 1511-1518.

[11] S.W. Davies, M. Turmaine, B.A. Cozens, M. DiFiglia, A.H. Sharp, C.A. Ross, E. Scherzinger, E.E. Wanker, L. Mangiarini, G.P. Bates, Formation of neuronal intranuclear inclusions underlies the neurological dysfunction in mice transgenic for the HD mutation, Cell 90 (1997) 537-548.

[12] M. DiFiglia, E. Sapp, K.O. Chase, S.W. Davies, G.P. Bates, J.P. Vonsattel, N. Aronin, Aggregation of huntingtin in neuronal intranuclear inclusions and dystrophic neurites in brain, Science 277 (1997) 1990-1993.

[13] P. Fernagut, E. Diguet, N. Stefanova, M. Biran, G. Wenning, P. Canioni, P. Bioulac, F. Tison, Subacute systemic 3-nitropropionic acid intoxication induces a distinct motor disorder in adult C57Bl/6 mice: behavioural and histopathological characterisation, Neuroscience 114 (2002) 755-759.

[14] P. Fernandez-Funez, M.L. Nino-Rosales, B. de Gouyon, W.C. She, J.M. Luchak, P. Martinez, E. Turiegano, J. Benito, M. Capovilla, P.J. Skinner, A. McCall, I. Canal, H.T. Orr, H.Y. Zoghbi, J. Botas, Identificatio of genes that modify ataxin-1-induced neurodegeneration, Nature 408 (2000) 101-106.

[15] R.J. Ferrante, O.A. Andreassen, B.G. Jenkins, A. Dedeoglu, S. Kuemmerle, J.K. Kubilus, R. Kaddurah-Daouk, S.M. Hersch, M.F. Beal, Neuroprotective effects of creatine in a transgenic mouse model of Huntington's disease, J. Neurosci. 20 (2000) 4389-4397.

[16] J.R. Glover, S. Lindquist, Hsp104, Hsp70, and Hsp40: a novel chaperone system that rescues previously aggregated proteins, Cell 94 (1998) 73-82.

[17] J.F. Gusella, M.E. MacDonald, Molecular genetics: unmasking polyglutamine triggers in neurodegenerative disease, Nat. Rev. Neurosci. 1 (2000) 109-115.

[18] O. Hansson, A. Petersen, M. Leist, P. Nicotera, R.F. Castilho, P. Brundin, Transgenic mice expressing a Huntington's disease mutation are resistant to quinolinic acid-induced striatal excitotoxicity, Proc. Natl. Acad. Sci. USA 96 (1999) 8727-8732.

[19] O. Hansson, R.F. Castilho, G.S. Kaminski Schierle, J. Karlsson, P. Nicotera, M. Leist, P. Brundin, Additive effects of caspase inhibitor and lazaroid on the survival of transplanted rat and human embryonic dopamine neurons, Exp. Neurol. 164 (2000) 102-111.

[20] N.R. Jana, M. Tanaka, G. Wang, N. Nukina, Polyglutamine lengthdependent interaction of Hsp40 and Hsp70 family chaperones with truncated N-terminal huntingtin: their role in suppression of aggregation and cellular toxicity, Hum. Mol. Genet. 9 (2000) 2009-2018.

[21] N.R. Jana, E.A. Zemskov, G. Wang, N. Nukina, Altered proteasomal function due to the expression of polyglutamine-expanded truncated 
$\mathrm{N}$-terminal huntingtin induces apoptosis by caspase activation through mitochondrial cytochrome c release, Hum. Mol. Genet. 10 (2001) 1049-1059.

[22] Y. Jiao, Z. Sun, T. Lee, F.R. Fusco, T.D. Kimble, C.A. Meade, S. Cuthbertson, A. Reiner, A simple and sensitive antigen retrieval method for free-floatin and slide-mounted tissue sections, J. Neurosci. Methods 93 (1999) 149-162.

[23] J.L. Johnson, E.A. Craig, Protein folding in vivo: unraveling complex pathways, Cell 90 (1997) 201-204.

[24] P. Kazemi-Esfarjani, S. Benzer, Genetic suppression of polyglutamine toxicity in Drosophila, Science 287 (2000) 1837-1840.

[25] Y. Kobayashi, A. Kume, M. Li, M. Doyu, M. Hata, K. Ohtsuka, G. Sobue, Chaperones Hsp70 and Hsp40 suppress aggregate formation and apoptosis in cultured neuronal cells expressing truncated androgen receptor protein with expanded polyglutamine tract, J. Biol. Chem. 275 (2000) 8772-8778.

[26] S. Krobitsch, S. Lindquist, Aggregation of huntingtin in yeast varies with the length of the polyglutamine expansion and the expression of chaperone proteins, Proc. Natl. Acad. Sci. USA 97 (2000) 1589-1594.

[27] L. Mangiarini, K. Sathasivam, M. Seller, B. Cozens, A. Harper, C. Hetherington, M. Lawton, Y. Trottier, H. Lehrach, S.W. Davies, G.P. Bates, Exon 1 of the HD gene with an expanded CAG repeat is sufficien to cause a progressive neurological phenotype in transgenic mice, Cell 87 (1996) 493-506.

[28] A.J. Morton, M.A. Lagan, J.N. Skepper, S.B. Dunnett, Progressive formation of inclusions in the striatum and hippocampus of mice transgenic for the human Huntington's disease mutation, J. Neurocytol. 29 (2000) 679-702.

[29] P.J. Muchowski, G. Schaffar, A. Sittler, E.E. Wanker, M.K. HayerHartl, F.U. Hartl, Hsp70 and hsp40 chaperones can inhibit selfassembly of polyglutamine proteins into amyloid-like fibrils Proc. Natl. Acad. Sci. USA 97 (2000) 7841-7846.

[30] K. Ohtsuka, T. Suzuki, Roles of molecular chaperones in the nervous system, Brain Res. Bull. 53 (2000) 141-146.

[31] P.H. Reddy, V. Charles, M. Williams, G. Miller, W.O. Whetsell Jr., D.A. Tagle, Transgenic mice expressing mutated full-length HD cDNA: a paradigm for locomotor changes and selective neuronal loss in Huntington's disease, Philos. Trans. R. Soc. Lond. B. Biol. Sci. 354 (1999) 1035-1045.

[32] S.H. Satyal, E. Schmidt, K. Kitagawa, N. Sondheimer, S. Lindquist, J.M. Kramer, R.I. Morimoto, Polyglutamine aggregates alter protein folding homeostasis in Caenorhabditis elegans, Proc. Natl. Acad. Sci. USA 97 (2000) 5750-5755.

[33] F. Saudou, S. Finkbeiner, D. Devys, M.E. Greenberg, Huntingtin acts in the nucleus to induce apoptosis but death does not correlate with the formation of intranuclear inclusions, Cell 95 (1998) 55-66.

[34] A.J. Silva, E.M. Simpson, J.S. Takahashi, H. Lipp, S. Nakanishi, J.M. Wehner, K.P. Giese, T. Tully, T. Abel, P.F. Chapman, K. Fox, S. Grant, S. Itohara, R. Lathe, M. Mayford, J.O. McNamara, R.J. Morris, M. Picciotto, J. Roder, H. Shin, P.A. Slesinger, D.R. Storm, M.P. Stryker, S. Tonegawa, Y. Wang, D.P. Wolfer, Mutant mice and neuroscience: recommendations concerning genetic background, Neuron 19 (1997) 755-759.

[35] S.S. Sisodia, Nuclear inclusions in glutamine repeat disorders: are they pernicious, coincidental, or beneficial? Cell 95 (1998) 1-4.
[36] D.L. Stenoien, C.J. Cummings, H.P. Adams, M.G. Mancini, K. Patel, G.N. DeMartino, M. Marcelli, N.L. Weigel, M.A. Mancini, Polyglutamine-expanded androgen receptors form aggregates that sequester heat shock proteins, proteasome components and SRC-1, and are suppressed by the HDJ-2 chaperone, Hum. Mol. Genet. 8 (1999) 731-741.

[37] S.T. Suhr, M.C. Senut, J.P. Whitelegge, K.F. Faull, D.B. Cuizon, F.H. Gage, Identities of sequestered proteins in aggregates from cells with induced polyglutamine expression, J. Cell. Biol. 153 (2001) 283-294.

[38] The Huntington's Disease Collaborative Research Group, A novel gene containing a trinucleotide repeat that is expanded and unstable on Huntington's disease chromosomes, Cell 72 (1993) 971-983.

[39] A.J. Tobin, E.R. Signer, Huntington's disease: the challenge for cell biologists, Trends Cell. Biol. 10 (2000) 531-536.

[40] Y. Trottier, Y. Lutz, G. Stevanin, G. Imbert, D. Devys, G. Cancel, F. Saudou, C. Weber, G. David, L. Tora et al., Polyglutamine expansion as a pathological epitope in Huntington's disease and four dominant cerebellar ataxias, Nature 378 (1995) 403-406.

[41] M. Turmaine, A. Raza, A. Mahal, L. Mangiarini, G.P. Bates, S.W. Davies, Nonapoptotic neurodegeneration in a transgenic mouse model of Huntington's disease, Proc. Natl. Acad. Sci. USA 97 (2000) 8093-8097.

[42] A. van Dellen, C. Blakemore, R. Deacon, D. York, A.J. Hannan, Delaying the onset of Huntington's in mice, Nature 404 (2000) $721-722$.

[43] A. van Dellen, R. Deacon, D. York, C. Blakemore, A.J. Hannan, Anterior cingulate cortical transplantation in transgenic Huntington's disease mice, Brain Res. Bull. 56 (2001) 313-318.

[44] J.P. Vonsattel, M. DiFiglia, Huntington disease, J. Neuropathol. Exp. Neurol. 57 (1998) 369-384.

[45] S. Waelter, A. Boeddrich, R. Lurz, E. Scherzinger, G. Lueder, H. Lehrach, E.E. Wanker, Accumulation of mutant huntingtin fragments in aggresome-like inclusion bodies as a result of insufficien protein degradation, Mol. Biol. Cell. 12 (2001) 1393-1407.

[46] E.E. Wanker, Protein aggregation and pathogenesis of Huntington's disease: mechanisms and correlations, Biol. Chem. 381 (2000) 937-942.

[47] J.M. Warrick, H.Y. Chan, G.L. Gray-Board, Y. Chai, H.L. Paulson, N.M. Bonini, Suppression of polyglutamine-mediated neurodegeneration in Drosophila by the molecular chaperone HSP70, Nat. Genet. 23 (1999) 425-428.

[48] A. Yamamoto, J.J. Lucas, R. Hen, Reversal of neuropathology and motor dysfunction in a conditional model of Huntington's disease, Cell 101 (2000) 57-66.

[49] C. Zander, J. Takahashi, K.H. El Hachimi, H. Fujigasaki, V. Albanese, A.S. Lebre, G. Stevanin, C. Duyckaerts, A. Brice, Similarities between spinocerebellar ataxia type 7 (SCA7) cell models and human brain: proteins recruited in inclusions and activation of caspase-3, Hum. Mol. Genet. 10 (2001) 2569-2579.

[50] H. Zhou, S.H. Li, X.J. Li, Chaperone suppression of cellular toxicity of huntingtin is independent of polyglutamine aggregation, J. Biol. Chem. 276 (2001) 48417-48424. 